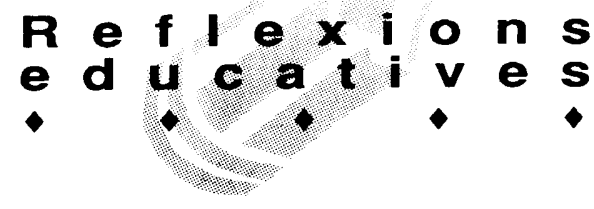

\title{
CRÒNICA D'UN ALTRE "DREAM TEAM"
}

\author{
Josep Maria Cornadó. Pedagog de l'EAP T-07 i ex-director d'Escola
}

En aquest article el lector pot estar tranquil, ja que no s'insistirà sobre el bon joc de l'equip de bàsquet dels USA; més aviat exposaré unes idees sobre un altre "TEAM" però que no és "DREAM": almenys la meva experiència, molt enriquidora per altra banda, m'ha portat a pensar així.

Avui és tremendament difícil parlar de temes educatius. El moment és molt complicat, es respira un clima de crispació, els educadors estan desencantats, professionalment parlant hi ha un futur incert, les coses estan canviant molt de pressa, i tot i que els mestres ja estem acostumats a "seguir roda", el ritme que s'està marcant ara és tot un repte.

Un membre de l'equip de redacció em va animarun dia perquè col.laborés amb la revista, i jo li vaig contestar que al setembre tindria un article meu, que a mi m'agrada escriure, no tant pel fet que els altres ho puguin llegir, com per l'exercici d'aclariment d'idees que he de fer quan em trobo davant l'ordinador. M'agrada pensar a poc a poc, m'agrada corregir, m'agrada veure com en qüestió de poc temps, el que ahir em semblava obvi, avui em pot semblar, si més no, discutible, i no oblidem que en matèra educativa, TOT ES DISCUTIBLE.

Una nit d'agost, calorosa i humida com totes, llegia la premsa amb l'objectiu de cansar els meus ulls, amb l'aparell de TV que donava en directe un partit de bàsquet en què sols jugava un equip, el "Dream Team"; al diari sols llegia que si "el Dream Team" amunt, que si avall, que si ¡Quin espectacle!, i sense adonar-me'n quasi vaig començar a ferparal.lelismes, i com els educadors sempre estem pensant en el mateix, òbviament les Olimpiades em recordaven el curs escolar, els atletes eren els membres de la comunitat educativa, el COOB era com un Consell Escolar, etc... i el Dream Team? Podia ser ... I'Equip Directiu, sí. Ja sabia el títol de l'article a què m'havia compromès.

Es cert: a l'estil de Jordan, Johnson, Barkley, Bird i companyia, cada curs escolar hi ha uns artistes que fan de la tasca escolar un espectacle, sense medalles, sense diners, sense reconeixements, però amb faltes personals, taps, cistelles de tres i amb molta responsabilitat.

Els equips directius de les escoles d'aquest pais han de ser els veritables conductors de la Reforma, per a la qual no sé si estan suficientment preparats, els protagonistes d'un canvi que desconeixen, i els responsables que tot surti bé.

El director, un agent polític (escollit per votació) que si fa el que cal es posa a tothom en contra, i si fa el que tothom vol no està fent el que cal i no exerceix les seves funcions amb responsabilitat, ha de patir les pressions dels pares, dels companys, dels alumnes, dels

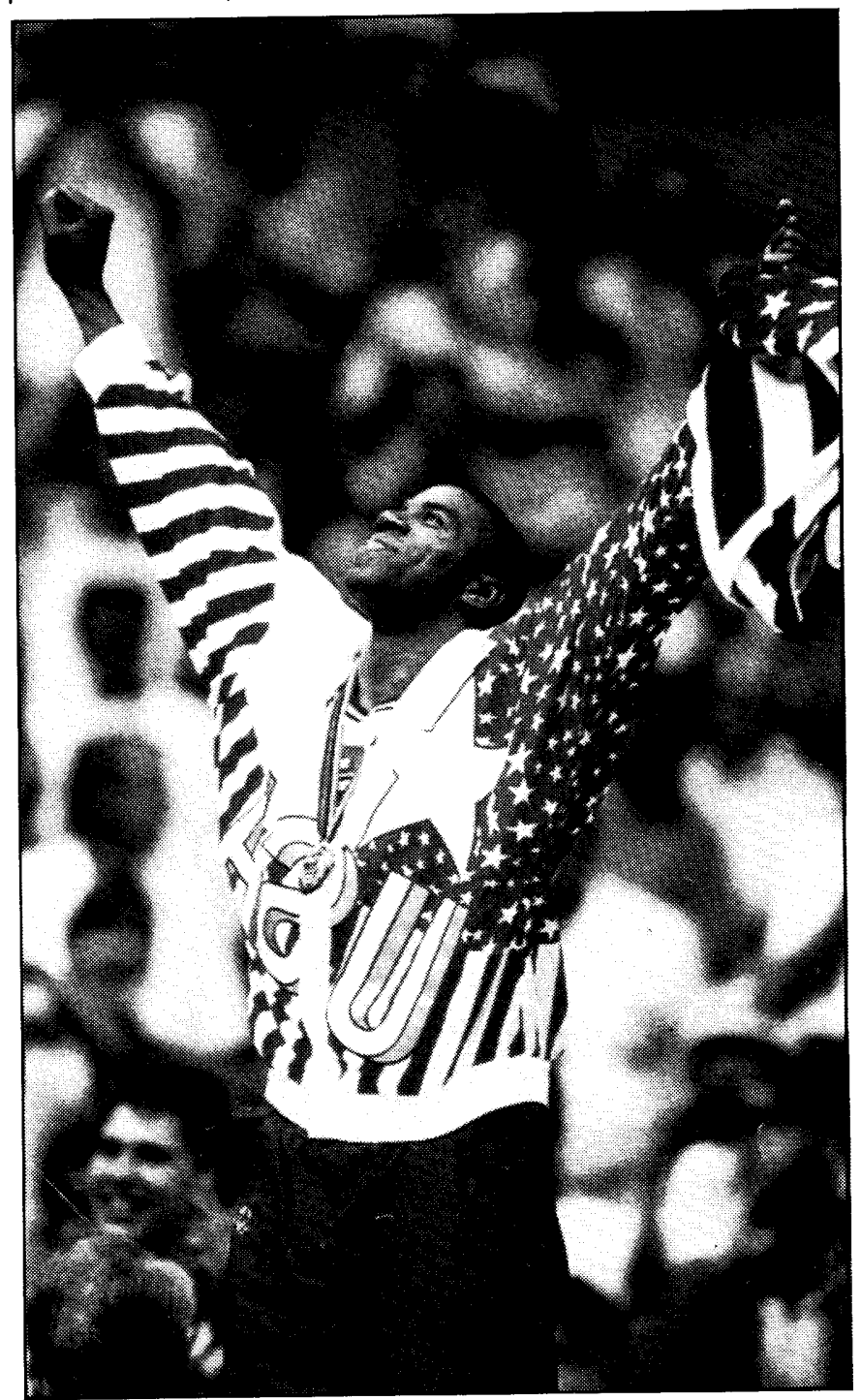




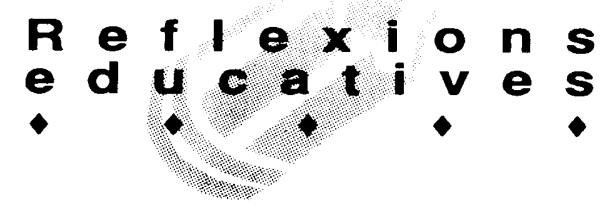

representants de l'administració municipal i educativa, i ha d'apendre a ballar Rock, Break dance, Swim i fins i tot la lambada i mai no xafar el peu al company de ball, i si no ets Fred Astaire, això és molt difícil.

Normalment, quan ja ha assumit el seu paper i ha après la seva funció, cansat i cremat no vol continuar i ho deixa per a un altre i és que ha d'aprendre tot sol a fer una tasca en la qual ha de manar sense manar, animar a desanimats, vigilar sense vigilar, decidir sense decidir massa, i en definitiva fer sense fer.

Sembla que fa menys que tothom, fent més que ningú (sempre hi ha excepcions), però té un consol: Els altres dos companys que pateixen com ell. El Cap d'Estudis i el Secretari. Com que continuo sense poder dormir, potser que em posi a veure una pel.lícula de video. He remenat i he trobat "El bueno, el feo i el malo". Pot ser divertit, no recordo com acaba!!

Jo no conec les intencions del alts dirigents escolars del país, però aquesta situació està demanant un canvi. El nostre Dream Team, cada vegada somia menys, cada vegada és més amateur, i aixó no és bo per a l'ensenyament.

A la fi del segle $X X$, en educació tenim l'oportunitat de començar bé, tenim un futur prometedor, perquè jo crec en la Reforma educativa: el marc teòric és excel.lent, els dissenys curriculars són bons, però, i perdoneu-me, hem tingut una "sortida falsa", i com en les curses de 100 metres, caldria repetir-la.

Les escoles necessiten equips directius preparats, que comptin amb tot el suport del món, i no voldria semblar reaccionari, però han de ser PROFESSIONALS, i fer "la feina ben feta, la que no té fronteres".

Quan jo necessito particularment un servei, exigeixo un bon professional, del que sigui, però una persona preparada per fer-ho. No és suficient la bona voluntat, la valentia, les ganes (infeliços..), tot aixó és un bon complement, un bon requisit, però cal fer les coses com cal, i més en educació; per tant, cal exigir preparació i també facilitar-la.

No m'imagino portant el cotxe al mecànic, i que em diguessin: "jo no sóc especialista en electricitat; però no pateixis, faré el que pugui". A fe de món, que el meu automòbil no es queda allà.

Fins que no surti un programa informàtic de Com ser director en dos disquets..., caldrà fer cursos, seminaris, taules rodones, reunions, donar facilitats, o si no passa el que passa. (almenys em passa el que m'ha passat).

El Cap d'estudis, (que bé treballa Clint Eastwood!! ), és el responsable pedagògic del centre, i al setembre ha començat la reforma, i ell ha de ... en teoria, dominar una situació, en què tot són dubtes i incerteses.

El Cap d'Estudis, crec que és el personatge més important del centre, l'animador de les activitats, el pont entre els pares i els educadors, i l'aqüeducte entre els professors $i$ els alumnes, $i$ té una gran responsabilitat conjuntament amb el Director: INNOVAR, fer possible la innovació, i crear les necessitats perquè es pugui desenvolupar amb exit.

El secretari (advocat-economista escolar), és el tercer en discòrdia, ha de portar els comptes com si fos un professional, quan normalment aporta una experiència d'economia familiar en el millor dels casos. és admirable això de portar el comptes i tenir-ho tot tant ben ordenat I desat, i saber-ho trobar quan fa falta, és una virtut que envejo.

Ells tres són tres - una paraula que em recorda medalles, podi, mosqueters, virtuts, Sudamericanos, S.O.S., Maries I porquets (amb perdó)-, els responsables del funcionament de les escoles avui i aqui, i puc afirmar que al contrari que al Dream Team de veritat, aquests sí que necessiten que la sort els acompanyl.

L'alumne viu en aquesta situació tan "sui generis" els anys més importants de la seva vida i desenvolupa les capacitats d'aprenentatge. D'aprenentatge de què? Esperem que discrimini i no aprengui tot el que veu sinó tan sols algunes actituds que des de l'escola s'intenten desenvolupar.

Ja no sé si el títol de l'article és tan afortunat com em semblava al començar-lo, i és que acabo de veure un espectacle tan important pertelevisió que els paral.lelismes de què parlava m'estan fent dubtar de moltes coses.

Les experiències, però, sempre són possitives, i almenys he descobert en quin Dream Team voldria estar, $i$ en quin mai no voldria ser seleccionat, (perquè de fet sempre m'han caigut millor els croats).

Potser ho he pintat molt negre, potser és aquesta calor la que em fa veure les coses aixi, potser sento enveja de Barkley, Bird i Jordan, potser ja estic cansat de tanta olimpiada... , ho deixo aqum perquè Lee Van Clift entra en el saloon i això es posa interessant. 